\title{
Review
}

\section{Translesion DNA Synthesis and Hsp90}

\author{
Takayuki Yamashita ${ }^{1}$, Tsukasa Oda and Takayuki Sekimoto \\ Laboratory of Molecular Genetics, The Institute for Molecular and Cellular Regulation, Gunma University, Gunma, Japan
}

(Received January 4, 2012; Revised March 1, 2012; Accepted March 2, 2012)

Translesion DNA synthesis (TLS) is an essential mechanism for DNA damage tolerance during genome duplication by bypassing DNA lesions with use of specialized lowfidelity polymerases. Thus, TLS is inherently mutagenic, which is presumed to be involved in cancer initiation and progression. Increasing attention has focused on posttranslational regulatory mechanisms of TLS polymerases, including covalent modification (e.g., phosphorylation) and proteasomal degradation. In this review article, we focus on our findings on Hsp90-mediated regulation of TLS polymerases and discuss potential pharmacological effects of Hsp90 inhibitors in cancer therapy.

Key words: translesion DNA synthesis, Y-family polymerase, Hsp90

\section{Introduction}

Precise and efficient duplication of the genome is essential for faithful inheritance of genetic information and maintenance of cellular architecture in multi-cellular organisms. Failure in this process causes various pathological disorders associated with mutations, genomic rearrangements and cell death, including cancers and degenerative diseases. Normal replication is hampered by various types of DNA damage on the template generated by environmental genotoxic agents (e.g., UV light and chemicals) and endogenous metabolic products (e.g., reactive oxygen species). Although most of these DNA lesions are removed by highly-coordinated multiple DNA repair pathways, some unrepaired lesions block the progression of replication forks catalyzed by high-fidelity DNA polymerases (Pols), which may lead to downstream re-initiation of DNA synthesis leaving single-stranded DNA gaps. Translesion DNA synthesis (TLS) is an essential mechanism for bypassing such replication blocks and post-replicative gaps by employing specialized TLS Pols, including Pol $\eta$, Pol $\kappa$, Pol $l$ and REV1, members of the Y-family Pols (Y-Pols), and Pol $\zeta$, a member of the B-family (Fig. 1) (1-5). These TLS Pols display low stringency for the active site and a lack of proofreading, thus they potentially contribute to mutagenesis as well as to DNA damage tolerance.
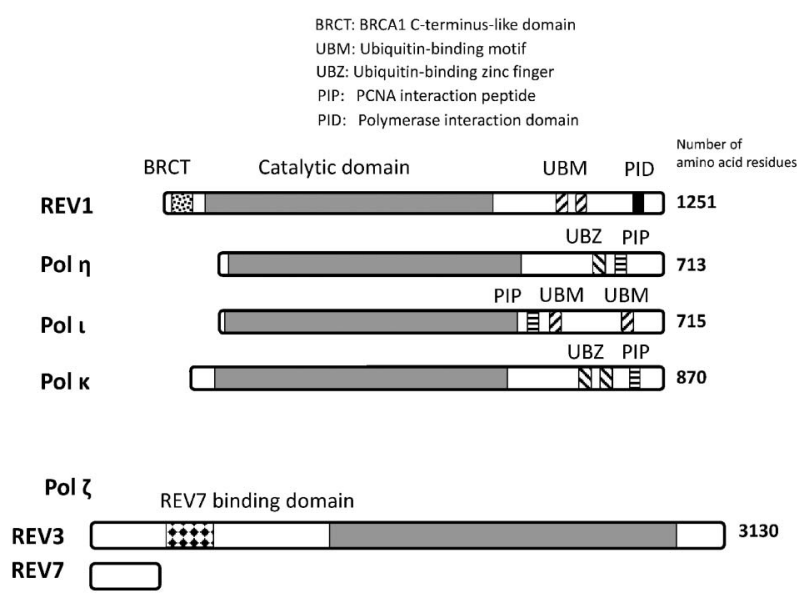

Fig. 1. Structures of TLS polymerases.

\section{Regulatory Mechanisms of TLS Pols}

Accumulating evidence has revealed that functions of TLS Pols are tightly regulated at different levels. One critical step is localization of TLS polymerases "at the right place at the right time". For this purpose, covalent modification of PCNA, an accessory factor of DNA polymerases, has an essential role. When replication stalls at sites of DNA damage, PCNA is monoubiquitinated at K164 by the Rad6/Rad18 complex and/or CRL4 $^{\text {Cdt2 }}$ ubiquitin ligase (6-8). Y-Pols associate with PCNA via PCNA-interacting domains such as PIPs, but they bind to a monoubiquitinated form of PCNA (Ub-PCNA) with much higher affinity via their ubiquitin-binding domains such as UBZs and UBMs (Figs. 1 and 2), thereby replacing high-fidelity replicative Pols (Fig. 3) (9-13). In addition, REV1-mediated proteinprotein interactions have critical roles in the regulation of TLS. Although REV1 has a deoxycytidyl transferase activity, this catalytic activity is dispensable for REV1mediated TLS (14). Several studies indicate the functional importance of the N-terminal BRCT domain, which is partly explained by its binding to PCNA

${ }^{1}$ Correspondence to: Takayuki Yamashita, Laboratory of Molecular Genetics, The Institute for Molecular and Cellular Regulation, Gunma University, 3-39-15 Showa-machi, Maebashi, Gunma 371-8512, Japan. Tel: +81-27-220-8830, Fax: +81-27-220-8834, E-mail: y-taka (a) showa.gunma-u.ac.jp 


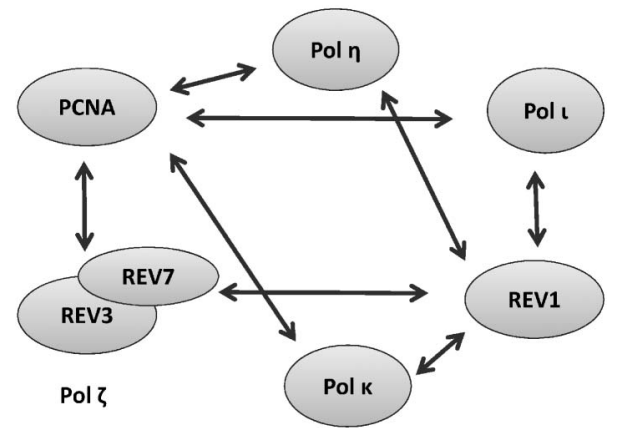

Fig. 2. Interactions between proteins involved in TLS (modified from Ref. 2).

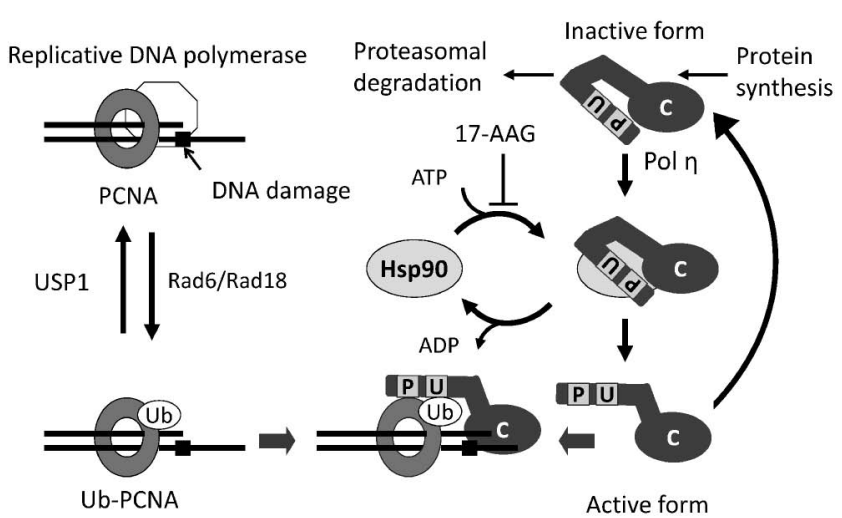

Fig. 3. Hypothetical model of Hsp90-mediated regulation of Pol $\eta$ targeting for TLS (modified from Ref. 44). Two major regulatory pathways are illustrated. Stalling of a replicative DNA polymerase at a site of DNA damage induces Rad6/Rad18-mediated generation of Ub-PCNA, whereas USP1 deubiquitinates Ub-PCNA. Pol $\eta$ is in a cycle between an active form and an inactive form, and transient association with Hsp90 facilitates $\mathrm{Pol} \eta$ folding into the active form. PIP (P), UBZ (U) and catalytic (C) domains of Pol $\eta$ are schematically shown. In the inactive form, PIP and UBZ are masked by intramolecular (or intermolecular) mechanisms. When 17-AAG inhibits the ATP-dependent chaperone cycle of Hsp90, a pool of the active form decreases; and an increased pool of the inactive form is targeted to proteasomal degradation. Hsp90 regulates REV1 by similar mechanisms.

$(12,15,16)$. In addition, REV1 has a C-terminal region that binds Pol $\eta$, Pol $\kappa$ and Pol $l$ as well as $\mathrm{Pol} \zeta$, a heterodimer of REV3 and REV7 (Figs. 1 and 2) (17-21), and recent findings indicate the functional significance of these interactions (21-23). Thus, it is proposed that REV1 acts as a scaffold protein to coordinate TLS polymerase switching (1-5).

Increasing attention has focused on conformational and stability control of TLS Pols by post-translational mechanisms, including covalent-modification, proteasomal degradation and chaperone-mediated folding. Earlier studies indicated that the chaperone/proteasome system has an important role in the regulation of Y-Pols in bacteria and lower eukaryotes. In Escherichia coli, the GroE chaperone helps Y-Pols fold correctly to function $(24,25)$; and, in Saccharomyces cerevisiae, the proteasome controls Pol $\eta$ stability and modulates mutagenesis (26-28). In recent studies, Pol $\eta$ and REV1, conserved throughout the eukaryotes, have been extensively studied. Various types of covalent modifications, including monoubiquitination, phosphorylation and sumoylation, are reported to regulate protein interactions and stability of Pol $\eta$ in higher eukaryotes (29-32). Chen and colleagues reported that Pirh2 and Mdm2 ubiquitin ligases are involved in UV-induced proteasomal degradation of Pol $\eta$ in human cells $(33,34)$. As to the regulation of Rev1, most of our knowledge is based on studies in yeasts. In Saccharomyces cerevisiae, Mec1 protein kinase, the ortholog of human ATR, phosphorylates Rev1, promoting efficiency of mutagenic TLS in a Pol $\zeta$-dependent manner (35-37). Yeast Rev1 protein levels increase to be $\sim 50$-fold higher during the G2/M phase compared to during the G1 and S phases, whereas its transcript levels vary only $\sim 3$-fold over the same phases, suggesting post-transcriptional control of Rev1 levels (38). Indeed, a recent study revealed that proteasomal degradation is involved in cell cycle-linked Rev1 regulation (39).

\section{Hsp90: A Promising Target for Cancer Therapeutics}

Hsp90 is an abundant, evolutionarily conserved molecular chaperone, which has a vital role in conformational regulation of a relatively selective group of 'client' proteins $(40,41)$. This function of Hsp90 depends on its ability to bind and hydrolyze ATP. Hsp90 not only promotes proper folding of newly synthesized proteins into mature forms but also regulates stability, trafficking, and protein-protein interactions of mature clients. To fulfill these functions, Hsp90 usually cooperates with Hsp70 and cochaperones, such as p23 and CDC37. Many Hsp90 clients play key roles in cell survival/growth; representative clients include receptor and non-receptor protein kinases (e.g., ErbB2 and Akt), steroid receptors, transcriptional factors (e.g., p53), telomerase and chromatin remodeling proteins. In addition, Hsp90 promotes stability and activity of mutant or over-expressed oncoproteins (42). Thus, Hsp90 is an attractive target for cancer therapeutics. Indeed, specific inhibitors of Hsp90 are under development as promising anti-tumor agents. For instance, geldanamycin, a benzoquinone ansamycin antibiotic with potent anti-tumor activity, binds to the ATP-binding pocket of $\mathrm{Hsp} 90$ and inhibits its function. Because of its toxicity in animal models, several less toxic derivatives, including 17-allylamino-17-demethoxygeldanamycin (17-AAG), were developed and entered clinical trials a decade ago; a dozen of different classes of Hsp90 inhibitors are currently in clinical trials (42). Thus, un- 
derstanding pharmacological effects of Hsp90 inhibitors would provide new insights into clinical effects of the drugs.

\section{Hsp90 Regulates Pol $\eta$ and REV1-mediated TLS}

Some preclinical studies documented that Hsp90 inhibitors and genotoxic agents have synergistic effects in tumor cell killing, raising the possibility that Hsp90 regulates DNA damage response. Indeed, some proteins in the DNA damage response network, such as Chk1 and FANCA, were shown to be Hsp90 clients (43-45). We recently identified $\mathrm{Hsp} 90$ as an essential regulator of two major Y-Pols, Pol $\eta$ and REV1 (46,47) (Fig. 3).

Our recent work provided several lines of evidence establishing that Pol $\eta$ and REV1 are clients of Hsp90 $(46,47)$. First, Hsp90 specifically interacted with these Pols in vivo and in vitro. Another line of evidence is that 17-AAG suppresses UV-induced accumulation of Pol $\eta$ and REV1 at replication foci. In most cell types, 17-AAG reduced protein levels of these polymerases by accelerating proteasomal degradation. Moreover, RNAi-mediated depletion of Hsp90 reduced $\mathrm{Pol} \eta$ protein levels and UV-induced focus formation. Thus, Pol $\eta$ and REV1 have the typical features of Hsp90 clients.

Importantly, the mild reduction of Pol $\eta$ and REV1 in HEK293T cells allowed us to find that Hsp90 regulates the binding of these Y-Pols to Ub-PCNA. 17-AAG significantly suppressed the interaction between $\mathrm{Pol} \eta$ or REV1 and Ub-PCNA in chromatin immunoprecipitation. Furthermore, Pol $\eta$ and REV1 extracted from 17AAG-treated cells exhibited low binding to PCNA and/or Ub in vitro. Based on these results, we proposed a model in which the Hsp90 chaperone cycle is required for the folding of Pol $\eta$ into an active form to enable efficient Ub-PCNA binding.

Finally, we showed that Hsp90 promotes $\mathrm{Pol} \eta$ - and REV1-mediated TLS by evaluating mutation rates in the supF reporter gene $(46,47)$. However, these two Y-Pols have opposite effects on UV-induced mutagenesis: Pol $\eta$ is engaged in error-free TLS across UV-induced thymine dimers, suppressing UV-induced mutagenesis; whereas REV1 is engaged in error-prone TLS, promoting UV-induced mutagenesis. Thus, the question arises what is the overall regulatory role of $\mathrm{Hsp} 90$ for TLS, although our knowledge is too premature to answer this question. In a current model, TLS consists of two major processes, insertion and extension: first, a TLS polymerase incorporates nucleotides opposite DNA lesions and then a second TLS polymerase extends a few additional nucleotides before restart of replicative DNA synthesis (1-5). Consistent with this model, recent studies indicate that UV-induced cyclobutane pyrimidine dimers are bypassed by $\operatorname{Pol} \eta$ by itself, whereas a combination of Pol $l$ or Pol $\kappa$-mediated error-prone insertion and a Pol $\zeta$ mediated extension has a major role in mutagenic TLS across the DNA lesion in Pol $\eta$-deficient cells (48-50). REV1 may function in the latter mutagenic TLS pathway through its interaction with Pol $l$ and Pol $\kappa$ as well as Pol $\zeta$, possibly facilitating a switch of Pols, although this regulatory function of REV1 in TLS is poorly defined. In this context, Hsp90 inhibition can have apparently paradoxical effects on UV-induced mutagenesis in Pol $\eta$ expressing and Pol $\eta$-deficient cells: Hsp90 suppresses and promotes UV-induced mutagenesis in the presence and absence of Pol $\eta$, respectively $(46,47)$. Thus, the impact of Hsp90 inhibition probably depends on what TLS pathways and DNA lesions predominate.

\section{TLS: A Novel Target of Hsp90 Inhibitors?}

Carcinogenic activities of genotoxic agents, such as $\mathrm{UV}$ and benzo[a]pyrene, are mainly mediated by introduction of point mutations through error-prone TLS. Indeed, recent genomic analyses of cell lines derived from a melanoma and a lung cancer indicated that the majority of mutations were derived from mutagenic TLS across DNA lesions induced by UV and carcinogenic chemicals contained in tobacco smoke, respectively $(51,52)$. Furthermore, several studies indicate that Pol $\eta$ and REV1 contribute to cancer initiation and progression. For instance, it was proposed that $\mathrm{Pol} \eta$ is involved in mutagenic TLS across oxidative DNA damage generated by azathiopurine and UVA light, leading to occurrence of skin cancer in long-term survivors of organ transplantation (53). Furthermore, reduced expression of REV1 suppresses benzo[a]pyreneinduced development of lung cancer in mice (54), and cyclophosphamide-induced mutagenesis resulting in decreased acquisition of drug resistance in B-cell lymphoma transplanted in mice (55). Thus, Hsp90-targeting drugs may prevent TLS-mediated mutagenesis in vivo, thereby suppressing tumor initiation and/or progression.

Acknowledgements: We thank Franklin Mayca Pozo and Kyoko Tomizawa for their contribution to our work. We are also grateful to Fumio Hanaoka, Chikahide Masutani and Yoshiki Murakumo for helpful collaboration.

\section{References}

1 Friedberg EC, Lehmann AR, Fuchs RP. Trading places: how do DNA polymerases switch during translesion DNA synthesis? Mol Cell. 2005; 18: 499-505.

2 Lehmann AR, Niimi A, Ogi T, Brown S, Sabbioneda S, Wing JF, Kannouche PL, Green CM. Translesion synthesis: Y-family polymerases and the polymerase switch. DNA Repair (Amst). 2007; 6: 891-9.

3 Guo C, Kosarek-Stancel JN, Tang TS, Friedberg EC. Yfamily DNA polymerases in mammalian cells. Cell Mol Life Sci. 2009; 66: 2363-81. 
4 Ohmori H, Hanafusa T, Ohashi E, Vaziri C. Separate roles of structured and unstructured regions of Y-family DNA polymerases. Adv Protein Chem Struct Biol. 2009; 78: 99-146.

5 Waters LS, Minesinger BK, Wiltrout ME, D'Souza S, Woodruff RV, Walker GC. Eukaryotic translesion polymerases and their roles and regulation in DNA damage tolerance. Microbiol Mol Biol Rev. 2009; 73: 134-54.

6 Hoege C, Pfander B, Moldovan GL, Pyrowolakis G, Jentsch S. RAD6-dependent DNA repair is linked to modification of PCNA by ubiquitin and SUMO. Nature. 2002; 419: 135-41.

7 Watanabe K, Tateishi S, Kawasuji M, Tsurimoto T, Inoue $\mathrm{H}$, Yamaizumi M. Rad18 guides $\operatorname{pol} \eta$ to replication stalling sites through physical interaction and PCNA monoubiquitination. EMBO J. 2004; 23: 3886-96.

8 Terai K, Abbas T, Jazaeri AA, Dutta A. CRL4 ${ }^{\text {Cdt2 }}$ E3 ubiquitin ligase monoubiquitinates PCNA to promote translesion DNA synthesis. Mol Cell. 2010; 37: 143-9.

9 Bienko M, Green CM, Crosetto N, Rudolf F, Zapart G, Coull B, Kannouche P, Wider G, Peter M, Lehmann AR, Hofmann K, Dikic I. Ubiquitin-binding domains in Y-family polymerases regulate translesion synthesis. Science. 2005; 310: 1821-4.

10 Kannouche PL, Wing J, Lehmann AR. Interaction of human DNA polymerase $\eta$ with monoubiquitinated PCNA: a possible mechanism for the polymerase switch in response to DNA damage. Mol Cell. 2004; 14: 491-500.

11 Plosky BS, Vidal AE, Fernández de Henestrosa AR, McLenigan MP, McDonald JP, Mead S, Woodgate R. Controlling the subcellular localization of DNA polymerases $l$ and $\eta$ via interactions with ubiquitin. EMBO J. 2006; 25: 2847-55.

12 Guo C, Sonoda E, Tang TS, Parker JL, Bielen AB, Takeda S, Ulrich HD, Friedberg EC. REV1 protein interacts with PCNA: significance of the REV1 BRCT domain in vitro and in vivo. Mol Cell. 2006; 23: 265-71.

13 Guo C, Tang TS, Bienko M, Parker JL, Bielen AB, Sonoda E, Takeda S, Ulrich HD, Dikic I, Friedberg EC. Ubiquitin-binding motifs in REV1 protein are required for its role in the tolerance of DNA damage. Mol Cell Biol. 2006; 26: 8892-900.

14 Nelson JR, Gibbs PE, Nowicka AM, Hinkle DC, Lawrence CW. Evidence for a second function for Saccharomyces cerevisiae Rev1p. Mol Microbiol. 2000; 37: 549-54.

15 Jansen JG, Tsaalbi-Shtylik A, Langerak P, Calléja F, Meijers CM, Jacobs H, de Wind N. The BRCT domain of mammalian Rev1 is involved in regulating DNA translesion synthesis. Nucleic Acids Res. 2005; 33: 356-65.

16 Jansen JG, Tsaalbi-Shtylik A, Hendriks G, Gali H, Hendel A, Johansson F, Erixon K, Livneh Z, Mullenders LH, Haracska L, de Wind N. Separate domains of Rev1 mediate two modes of DNA damage bypass in mammalian cells. Mol Cell Biol. 2009; 29: 3113-23.

17 Murakumo Y, Ogura Y, Ishii H, Numata S, Ichihara M, Croce CM, Fishel R, Takahashi M. Interactions in the error-prone postreplication repair proteins hREV1, hREV3, and hREV7. J Biol Chem. 2001; 276: 35644-51.
18 Guo C, Fischhaber PL, Luk-Paszyc MJ, Masuda Y, Zhou J, Kamiya K, Kisker C, Friedberg EC. Mouse Rev1 protein interacts with multiple DNA polymerases involved in translesion DNA synthesis. EMBO J. 2003; 22: 6621-30.

19 Ohashi E, Murakumo Y, Kanjo N, Akagi J, Masutani C, Hanaoka F, Ohmori H. Interaction of hREV1 with three human Y-family DNA polymerases. Genes Cells. 2004; 9: 523-31.

20 Kosarek JN, Woodruff RV, Rivera-Begeman A, Guo C, D'Souza S, Koonin EV, Walker GC, Friedberg EC. Comparative analysis of in vivo interactions between Rev1 protein and other Y-family DNA polymerases in animals and yeasts. DNA Repair (Amst). 2008; 7: 439-51.

21 Ohashi E, Hanafusa T, Kamei K, Song I, Tomida J, Hashimoto $\mathrm{H}$, Vaziri C, Ohmori H. Identification of a novel REV1-interacting motif necessary for DNA polymerase $\kappa$ function. Genes Cells. 2009; 14: 101-11.

22 Akagi J, Masutani C, Kataoka Y, Kan T, Ohashi E, Mori $\mathrm{T}$, Ohmori H, Hanaoka F. Interaction with DNA polymerase eta is required for nuclear accumulation of REV1 and suppression of spontaneous mutations in human cells. DNA Repair (Amst). 2009; 8: 585-99.

23 Andersen PL, Xu F, Ziola B, McGregor WG, Xiao W. Sequential assembly of translesion DNA polymerases at UV-induced DNA damage sites. Mol Biol Cell. 2011; 22: 2373-83.

24 Donnelly CE, Walker GC. groE mutants of Escherichia coli are defective in $u m u D C$-dependent UV mutagenesis. J Bacteriol. 1989; 171: 6117-25.

25 Layton JC, Foster PL. Error-prone DNA polymerase IV is regulated by the heat shock chaperone GroE in Escherichia coli. J Bacteriol. 2005; 187: 449-57.

26 Podlaska A, McIntyre J, Skoneczna A, SledziewskaGojska E. The link between 20 S proteasome activity and post-replication DNA repair in Saccharomyces cerevisiae. Mol Microbiol. 2003; 49: 1321-32.

27 McIntyre J, Baranowska H, Skoneczna A, Halas A, Sledziewska-Gojska E. The spectrum of spontaneous mutations caused by deficiency in proteasome maturase Ump1 in Saccharomyces cerevisiae. Curr Genet. 2007; 52: 221-8

28 Skoneczna A, McIntyre J, Skoneczny M, Policinska Z, Sledziewska-Gojska E. Polymerase eta is a short-lived, proteasomally degraded protein that is temporarily stabilized following UV irradiation in Saccharomyces cerevisiae. J Mol Biol. 2007; 366: 1074-86.

29 Chen YW, Cleaver JE, Hatahet Z, Honkanen RE, Chang JY, Yen Y, Chou KM. Human DNA polymerase $\eta$ activity and translocation is regulated by phosphorylation. Proc Natl Acad Sci USA. 2008; 105: 16578-83.

$30 \mathrm{Kim}$ SH, Michael WM. Regulated proteolysis of DNA polymerase $\eta$ during the DNA-damage response in $C$. elegans. Mol Cell. 2008; 32: 757-66.

31 Bienko M, Green CM, Sabbioneda S, Crosetto N, Matic I, Hibbert RG, Begovic T, Niimi A, Mann M, Lehmann AR, Dikic I. Regulation of translesion synthesis DNA polymerase $\eta$ by monoubiquitination. Mol Cell. 2010; 37: 396-407. 
32 Göhler T, Sabbioneda S, Green CM, Lehmann AR. ATR-mediated phosphorylation of DNA polymerase $\eta$ is needed for efficient recovery from UV damage. J Cell Biol. 2011; 192: 219-27.

33 Jung YS, Hakem A, Hakem R, Chen X. Pirh2 E3 ubiquitin ligase monoubiquitinates DNA polymerase eta to suppress translesion DNA synthesis. Mol Cell Biol. 2011; 31: 3997-4006.

34 Jung YS, Qian Y, Chen X. DNA polymerase eta is targeted by $\mathrm{Mdm} 2$ for polyubiquitination and proteasomal degradation in response to ultraviolet irradiation. DNA Repair (Amst). 2012; 11: 177-84.

35 Hirano Y, Sugimoto K. ATR homolog Mec1 controls association of DNA polymerase $\zeta$-Rev1 complex with regions near a double-strand break. Curr Biol. 2006; 16: 586-90.

36 Sabbioneda S, Bortolomai I, Giannattasio M, Plevani P, Muzi-Falconi M. Yeast Rev1 is cell cycle regulated, phosphorylated in response to DNA damage and its binding to chromosomes is dependent upon MEC1. DNA Repair (Amst). 2007; 6: 121-7.

37 Pagès V, Santa Maria SR, Prakash L, Prakash S. Role of DNA damage-induced replication checkpoint in promoting lesion bypass by translesion synthesis in yeast. Genes Dev. 2009; 23: 1438-49.

38 Waters LS, Walker GC. The critical mutagenic translesion DNA polymerase Rev1 is highly expressed during $\mathrm{G}_{2} / \mathrm{M}$ phase rather than $\mathrm{S}$ phase. Proc Natl Acad Sci USA. 2006; 103: 8971-6.

39 Wiltrout ME, Walker GC. Proteasomal regulation of the mutagenic translesion DNA polymerase, Saccharomyces cerevisiae Rev1. DNA Repair (Amst). 2011; 10: 169-75.

40 Pearl LH, Prodromou C. Structure and mechanism of the Hsp90 molecular chaperone machinery. Annu Rev Biochem. 2006; 75: 271-94.

41 Taipale M, Jarosz DF, Lindquist S. HSP90 at the hub of protein homeostasis: emerging mechanistic insights. Nat Rev Mol Cell Biol. 2010; 11: 515-28.

42 Trepel J, Mollapour M, Giaccone G, Neckers L. Targeting the dynamic HSP90 complex in cancer. Nat Rev Cancer. 2010; 10: 537-49.

43 Arlander SJ, Eapen AK, Vroman BT, McDonald RJ, Toft DO, Karnitz LM. Hsp90 inhibition depletes Chk1 and sensitizes tumor cells to replication stress. J Biol Chem. 2003; 278: 52572-7.

44 Oda T, Hayano T, Miyaso H, Takahashi N, Yamashita
T. Hsp90 regulates the Fanconi anemia DNA damage response pathway. Blood. 2007; 109: 5016-26.

45 Yamashita T, Oda T, Sekimoto T. Hsp90 and the Fanconi anemia pathway: a molecular link between protein quality control and the DNA damage response. Cell $\mathrm{Cy}$ cle. 2007 ; 6: 2232-5.

46 Sekimoto T, Oda T, Pozo FM, Murakumo Y, Masutani C, Hanaoka F, Yamashita T. The molecular chaperone Hsp90 regulates accumulation of DNA polymerase $\eta$ at replication stalling sites in UV-irradiated cells. Mol Cell. 2010; 37: 79-89.

47 Pozo FM, Oda T, Sekimoto T, Murakumo Y, Masutani C, Hanaoka F, Yamashita T. Molecular chaperone Hsp90 regulates REV1-mediated mutagenesis. Mol Cell Biol. 2011; 31: 3396-409.

48 Shachar S, Ziv O, Avkin S, Adar S, Wittschieben J, Reissner T, Chaney S, Friedberg EC, Wang Z, Carell T, Geacintov N, Livneh Z. Two-polymerase mechanisms dictate error-free and error-prone translesion DNA synthesis in mammals. EMBO J. 2009; 28: 383-93.

49 Ziv O, Geacintov N, Nakajima S, Yasui A, Livneh Z. DNA polymerase $\zeta$ cooperates with polymerases $\kappa$ and $\iota$ in translesion DNA synthesis across pyrimidine photodimers in cells from XPV patients. Proc Natl Acad Sci USA. 2009; 106: 11552-7.

50 Livneh Z, Ziv O, Shachar S. Multiple two-polymerase mechanisms in mammalian translesion DNA synthesis. Cell Cycle. 2010; 9: 729-35.

51 Pleasance ED, Stephens PJ, O’Meara S, McBride DJ, Meynert A, et al. A small-cell lung cancer genome with complex signatures of tobacco exposure. Nature. 2010; 463: 184-90.

52 Pleasance ED, Cheetham RK, Stephens PJ, McBride DJ, Humphray SJ, et al. A comprehensive catalogue of somatic mutations from a human cancer genome. Nature. 2010; 463: 191-6.

53 O'Donovan P, Perrett CM, Zhang X, Montaner B, Xu $\mathrm{YZ}$, et al. Azathioprine and UVA light generate mutagenic oxidative DNA damage. Science. 2005; 309: 1871-4.

54 Dumstorf CA, Mukhopadhyay S, Krishnan E, Haribabu B, McGregor WG. REV1 is implicated in the development of carcinogen-induced lung cancer. Mol Cancer Res. 2009; 7: 247-54.

55 Xie K, Doles J, Hemann MT, Walker GC. Error-prone translesion synthesis mediates acquired chemoresistance. Proc Natl Acad Sci USA. 2010; 107: 20792-7. 